\title{
Percepções dos professores sobre o uso do software Modellus em uma experiência de modelagem ${ }^{+*}$
}

\author{
Italo Gabriel Neide ${ }^{1}$ \\ Andréia Spessatto Maman ${ }^{1}$ \\ Maria Madalena Dullius ${ }^{1}$ \\ Adriana Belmonte Bergmann ${ }^{1}$ \\ Marli Teresinha Quartieri ${ }^{1}$ \\ Universidade do Vale do Taquari - Univates \\ Lajeado - RS
}

\section{Resumo}

Esta pesquisa de carácter qualitativo tem como objetivo apresentar os resultados obtidos em relação à utilização de uma modelagem computacional com o software Modellus num curso de formação continuada para professores da Educação Básica. O curso envolveu doze professores com formação nas áreas de Física, de Matemática e de Ciências Exatas, sendo que uma parte da formação foi destinada para o desenvolvimento de atividades de modelagem computacional envolvendo situações de cinemática, em especial o Movimento Retilíneo Uniforme (MRU). A fundamentação está embasada na modelagem computacional sob a luz de um ensino científico, em que se procura aproximar a forma que se faz ciência com a sala de aula. Os resultados apresentados neste trabalho apontam que de forma geral, a modelagem pode vir a potencializar a construção de aprendizagem do aluno. Em síntese surgiram três resultados relevantes. No curso de formação continuada foi observado que o compartilhamento de experiências de professores que desenvolveram atividades com recursos tecnológicos em sala de aula contribuiu com os professores que ainda não haviam utilizado a se sentirem mais seguros e confiantes, encorajaram os demais a trabalhar nas suas salas de aula

\footnotetext{
${ }^{+}$The perceptions of teachers about use of modellus software in a modeling experience

* Recebido: abril de 2018.

Aceito: abril de 2019.

${ }^{1}$ E-mails: italo.neide@univates.br; andreiah2o@univates.br; madalena@univates.br; aberg@univates.br; mtquartieri@univates.br
} 
atividades com recursos tecnológicos, bem como ao desenvolvimento de trabalhos conjuntos com seus pares durante a formação. Dois professores desenvolveram as atividades do Modellus em suas salas de aula, e apontaram a motivação, a visualização, as representações múltiplas e as aproximações da física com a matemática como principais diferenças quando comparadas com a forma tradicional que faziam. Por último, vale ressaltar as dificuldades técnicas enfrentadas pelos professores: falta de computadores, dificuldade para reservar o laboratório de informática, computadores antigos e internet lenta.

Palavras-chave: Ensino de Física; Modelagem Computacional; Tecnologias.

\begin{abstract}
This qualitative research aims to present the results obtained in relation to the use of a computational modeling with the Modellus software in a continuing education course for Basic Education teachers. The course involved twelve teachers with formation in Physics, Mathematics and Exact Sciences, and a part of the training was intended for the development of computational modeling activities involving kinematic situations, in particular Linear Motion (LM). The theoretical foundation is based on computational modeling under the light of a sientific teaching, in which it aims to approximate the way that science is done with the classroom. The results presented in this paper point out generally, that modeling can be a way of potentialize student learning. In summary, three relevant results have emerged. In the continuing education course, it was observed that the sharing of experiences of teachers who developed activities with technological resources in the classroom contributed with teachers who had not yet used them to feel more confident and safe, encouraged others to work in their classrooms activities with technological resources, as well as the development of joint work with their peers during the training. Two teachers developed the Modellus activities in their classrooms, and they pointed out motivation, visualization, multiple representations and approximations of physics with mathematics as the main differences compared to the traditional way they teach. Finally, it is worth mentioning the technical difficulties faced by teachers: lack of computers, difficulty to reserve the computer lab, old computers and slow internet.
\end{abstract}


Keywords: Physics Teaching; Computational Modeling; Technologies.

\section{Introdução}

Apesar de existirem muitas salas de aula em que os processos de ensino e de aprendizagem desenvolvidos ainda não contemplem a utilização dos recursos digitais, o Instituto Brasileiro de Geografia e Estatística (IBGE) em 2015 apresentou que mais de cinquenta por cento dos brasileiros têm acesso à internet em suas próprias casas ${ }^{2}$. Nos meios urbanos, o acesso à internet se tornou necessário para uns e parte de uma cultura para outros, esse último grupo sendo formado principalmente pelos jovens e crianças.

Aprender a falar, ler, escrever e estar vivenciando suas primeiras experiências em meio a um ambiente recheado de tecnologias traz uma ruptura na forma tradicional de se aprender (PRENSKY, 2001). Esse processo ocorre cotidianamente em casa, sendo que nas escolas já existe um movimento para sua inclusão, porém geralmente é lento e explorado sem propriedade. Pode-se citar como motivo gerador desse problema a falta de cursos voltados para o uso de tecnologias na formação inicial dos professores. Mesmo quando existem esses cursos, muitas vezes são trabalhados de uma forma demagógica frequentemente se utilizando de uma verborragia e ignorando a exploração prática com cunho pedagógico que pode ser realizada (SCHUHMACHER; PINHO ALVES; SCHUHMACHER, 2017).

Uma solução possível frente a essa problemática é o desenvolvimento de cursos de formação continuada que contemplem um uso dos recursos tecnológicos planejado para professores. Neste caminho, este trabalho pretende apresentar um recorte de uma pesquisa desenvolvida por um grupo de pesquisadores da Universidade do Vale do Taquari Univates, localizada na cidade de Lajeado, Rio Grande do Sul. Este grupo de pesquisa vem se preocupando com a temática do uso de recursos tecnológicos no ensino por sete anos e conta com pesquisadores das áreas de Ensino de Matemática e de Física.

Neste trabalho são descritas as implicações de se utilizar um software de modelagem, o Modellus $^{3}$, para trabalhar o conceito de Movimento Retilíneo Uniforme (MRU), através da óptica dos professores pesquisados participantes de um curso de formação continuada e dos estudantes da Educação Básica destes professores. O curso contemplou outras ações, sendo esta uma ação em específico. Aqui, são apresentados e analisados os momentos de criação de uma atividade de modelagem com o Modellus, sua validação, o desenvolvimento desta atividade durante o curso de formação e o desenvolvimento da mesma atividade pelos professores do curso de formação com seus alunos nas suas respectivas escolas.

Dentre as várias opções que os recursos tecnológicos oferecem, como os jogos digitais, os simuladores, a modelagem computacional (NEIDE; QUARTIERI, 2016), optou-se pela modelagem computacional para o desenvolvimento deste tema. Esta escolha é embasada

\footnotetext{
2 <http://www.bbc.com/portuguese/noticias/2015/04/150429_divulgacao_pnad_ibge_lgb>.

$3<$ http://docentes.fct.unl.pt/vdt/pages/modellus-software-documents>.
} 
sob a luz de um ensino científico (PIETROCOLA, 1999), descrito a seguir. Este grupo de pesquisa acredita que para se ensinar Física há a necessidade de possibilitar ao aluno uma experiência similar de como se dá o avanço epistemológico da ciência. Neste sentido há a necessidade de proporcionar momentos de formação, de questionamentos, de elaboração de hipóteses para solução, de modelagem para resolver o questionamento inicial e de validação do modelo obtido. Para tanto, optou-se pelo Modellus, pois é um software que foi desenvolvido para que seja possível inserir as equações de movimento da Física conforme a representação que os estudantes tradicionalmente trabalham. Este software também realiza a integração numérica necessária para simular o comportamento das grandezas físicas em questão, de forma que para o estudante esse processo se traduz em gráficos, tabelas e animações que surgem e evoluem em tempo real.

Num primeiro momento a modelagem foi desenvolvida apenas pelos professores participantes do curso. Uma vez com o modelo pronto, foram exploradas atividades com o objetivo de construir o conceito de velocidade média. Após esse passo, alguns professores levaram o modelo para os seus estudantes desenvolverem as atividades previamente elaboradas. Ressalta-se que como para muitos professores era a primeira vez que trabalhariam com recursos tecnológicos, os mesmos se sentiram mais seguros em levar o modelo pronto para explorar com seus alunos.

Diante do desenvolvimento da modelagem, da sua exploração pelas atividades durante o curso de formação e após os relatos das práticas com seus alunos pelos professores, podese perceber a potencialidade dessas ações no ensino, bem como a satisfação dos alunos ao experimentarem uma prática que privilegia a modelagem computacional e a exploração de elementos como visualização e animação por meio do Modellus.

Neste trabalho, serão apresentadas e analisadas as percepções dos professores participantes do curso durante o desenvolvimento das atividades com o grupo de pesquisadores e com seus alunos da educação básica.

\section{Referencial teórico}

No trabalho, "Modelos computacionais no ensino-aprendizagem de física: um referencial de trabalho" os autores, Araújo, Veit e Moreira (2012, p. 341) sintetizam a utilização da modelagem como: "tentativa de apreensão do real, ou suposto como tal, pelo pensamento". Segundo expressão dos próprios autores (Ibidem, 2012, p. 341.), "poucas frases capturam tão bem e em tão poucas palavras, a intenção primeira por trás do grandioso empreendimento humano conhecido como Ciências Naturais". Para os autores (Ibidem, 2012), mesmo com visões paradigmáticas distintas, físicos, químicos e biólogos, compartilham entre si a busca pela compreensão do mundo que nos cerca, investindo boa parte de seu tempo e recursos na construção, análise e aplicação de modelos científicos. "Esses modelos, peças fundamentais na construção do conhecimento científico, são elaborados a partir da observação diligente da 
natureza, razão, intuição, e, sobretudo, imaginação dos cientistas, não necessariamente nessa ordem" (ARAÚJO; VEIT; MOREIRA, 2012, p. 341).

Segundo Moreira (2014), o ensino de Ciências é desenvolvido de forma que "As teorias e modelos científicos são ensinados como verdades, como "descobertas geniais", como definitivos, acabados." (MOREIRA, 2014, p. 2). O autor enfatiza que os professores não apresentam os conhecimentos como construções científicas, e propõe o paradoxo de que "ensina-se ciências sem uma concepção do que é ciência" (Ibidem, 2014). Neste contexto uma possibilidade para se ensinar Ciências numa perspectiva científica seria por meio da modelagem computacional. Segundo o autor esta seria uma maneira do estudante aprender significativamente. E aprender significativamente implica em pensar, que envolve imaginar, fazer analogias, aproximações, comparações, informatizar, analisar, argumentar, tudo isso para que o estudante construa novos conhecimentos por meio da modelagem (MOREIRA, 2014).

No Ensino de Ciências é possível desenvolver esta interação entre o modelar e o aprender, e uma forma de mediar este processo é por meio das tecnologias. Um aplicativo que apresenta potencial nesse sentido para o ensino de Física é o software Modellus, o qual possibilita operar com funções da Física de forma simples e visual (TEODORO, 1998).

O software Modellus, é um programa livre desenvolvido de forma que permite ao aluno modelar ao inserir as equações de movimento e construir uma animação de elementos que representam as grandezas físicas do problema. Este software faz as integrações numéricas automaticamente num segundo plano, simplificando toda parte que envolveria programação, possibilitando ao aluno que se concentre principalmente com o ato de modelar.

Muitas são as vantagens para se trabalhar com o uso de atividades computacionais, Araújo, Veit e Moreira (2008) destacam as potencialidades dos experimentos virtuais por proporcionarem uma maior interação do estudante com a atividade, além de substituir experimentos reais caros, perigosos, complexos ou impossíveis de serem reproduzidos em uma sala de aula.

Outro aspecto relevante é o fato das atividades computacionais fornecerem múltiplas representações simultaneamente de um determinado fenômeno físico, (MEDEIROS e MEDEIROS, 2002). No caso do Modellus é possível que a linguagem algébrica (modelo), a tabela, o gráfico, a animação, sejam observadas/operadas conjuntamente nos mesmos intervalos de tempo.

A modelagem computacional desempenha um papel importante nos processos de ensino e de aprendizagem, pois existem problemas simples que podem ser abordados com a manipulação de alguns parâmetros dos sistemas de estudo. Conforme descreve Bona (2009, p. 2):

Muitos softwares educacionais estão se tornando uma solução reveladora e interessante, à medida que são empregados nas mais variadas situações tais como em simulações, que substituem sistemas físicos reais da vida profissional e testam diferentes alternativas de otimização desses sistemas. Além disto, podem também con- 
tribuir na estimulação do raciocínio lógico e, consequentemente, da autonomia, à medida que os alunos podem levantar hipóteses, fazer inferências e tirar conclusões, a partir dos resultados apresentados.

O aspecto da visualização é uma ação que deve ser levada em consideração, segundo os autores Borba e Vilarreal (2004, p. 96) “os processos de visualização atualmente atingiram uma nova dimensão se considerarmos o ambiente de aprendizagem computacional”. Neste sentido, Brandão, Araújo e Veit (2008, p. 12) destacam:

O computador, visto como uma ferramenta didática no auxílio da aprendizagem, pode fornecer oportunidades ímpares para a contextualização, visualização e apresentações das mais diversas situações físicas que possam dar sentido ao conceito físico que esteja sendo trabalhado pelo professor.

Porém, cabe ressaltar que a presença de recursos tecnológicos na prática pedagógica do professor, por si só não é garantia de maior qualidade na educação, pois os mesmos também podem ser utilizados para reforçar um ensino baseado na recepção e na mera reprodução de informações. Como apontam Coll, Mauri e Onrubia (2010, p. 75), docentes

[...] com uma visão mais transmissiva ou tradicional do ensino e da aprendizagem, tendem a utilizar as TIC para reforçar suas estratégias de apresentação e transmissão de conteúdos, enquanto aqueles que têm uma visão mais ativa ou "construtivista" tendem a utilizá-las para promover as atividades de exploração ou indagação dos alunos, o trabalho autônomo e o trabalho colaborativo.

Segundo Damasceno (2014), integrar as atuais tecnologias à sala de aula ainda é uma tarefa desafiadora para os professores e a formação inicial, na maior parte das vezes, ainda não aborda as tecnologias digitais, ou seja, o professor precisa buscar esse conhecimento em outros espaços. Para além da problemática da formação inicial, existem obstáculos difíceis de se transpor quando as tecnologias são abordadas em sala de aula. Pode-se citar, por exemplo, o planejamento das atividades a serem desenvolvidas, se fazem sentido ao contexto dos alunos, se de fato trazem algum elemento novo ou poderia se fazer o mesmo com outras ferramentas, enfim, este processo necessita de criatividade e criticidade para ter sucesso, e não realizar de qualquer forma (SCHUHMACHER; PINHO ALVES; SCHUHMACHER, 2017).

\section{Metodologia}

Na perspectiva de auxiliar os professores em sua formação com o uso de tecnologias na sala de aula realizou-se um curso de formação continuada na Universidade do Vale do Taquari Univates. Inscreveram-se no curso 22 professores da Educação Básica, das áreas de Matemática, Física e Ciências Exatas, sendo que todos tinham uma interface com a sala de aula. O objetivo do curso era a aproximação de aplicativos computacionais, do computador e do 
dispositivo tablet, como ferramentas de apoio pedagógico nas aulas de Matemática e de Física. Com carga horária de quarenta horas, foram desenvolvidas atividades que nortearam a utilização dos aplicativos, em consonância aos conteúdos explorados: estimativas, unidades de medida e ordens de grandeza, funções, trigonometria e cinemática.

Um dos momentos do curso foi destinado para o uso da modelagem computacional por meio do software Modellus. Neste encontro os participantes puderam desenvolver uma modelagem a partir do conteúdo de Movimento Retilíneo Uniforme (MRU), além de trabalharem e discutirem atividades desenvolvidas a partir da modelagem criada. As mesmas atividades, também foram desenvolvidas com os alunos dos professores participantes do curso, ou seja, estudantes da Educação Básica. O objetivo deste trabalho é apresentar os resultados obtidos deste momento de formação continuada em específico, bem como a impressão dos professores em realizar a modelagem computacional no Modellus.

Dessa maneira, a pesquisa de cunho qualitativa englobou todo o grupo dos 22 inscritos. Porém, somente foram considerados os dados daqueles sujeitos que concordaram em participar da pesquisa, socializar seus resultados com o grupo e que terminaram o curso de formação, a saber 12 professores. Neste trabalho, esses professores foram identificados pela nomenclatura Professor 1, Professor 2, etc.

Os instrumentos de coleta e análise de dados gerados durante o curso foram questionários, fotografias, gravações (áudio e vídeo) feitas durante a sequência dos encontros e as observações dos pesquisadores. Para este trabalho em específico foram analisados os questionários e as gravações de áudio.

A análise dos dados utilizada neste trabalho foi a descritiva. Em virtude dos dados obtidos, considerando os instrumentos de coleta de dados, descrever os fatos e interpretá-los sob a ótica do referencial teórico apresentado foi a opção que se apresentou com mais robustez frente as outras técnicas de análise de dados. Isso pode ser fundamentado pelo fato que os dados são constituídos principalmente de narrativas dos professores participantes do curso de formação, e de acordo com Fazenda, Tavares e Godoy (2015, p. 113) "O ato narrativo possibilita a reflexão sobre o processo investigado, a conscientização que produz a mudança, a construção de um caminho interdisciplinar.”.

Os questionários aplicados foram: questionário inicial aplicado antes do início da sequência didática e questionário aplicado após a atividade experimental. Estes questionários, baseados no instrumento de Santos (2009), tiveram a finalidade de, através da auto-avaliação dos professores, analisar o nível de motivação com o uso da ferramenta antes e após a atividade experimental, bem como se a sequência didática, usando metodologia e teorias diferentes, contribuiu para a melhoria da prática dos professores e consequentemente do aprendizado dos seus alunos. 


\section{Atividades desenvolvidas no Modellus}

Teodoro (1998) apresenta alguns aspectos da ferramenta computacional Modellus e discute as condições necessárias para um uso bem-sucedido do software. Em um primeiro momento, o autor define o conceito de modelo como uma representação simplificada de um sistema, não objetivando representar todas as características do mesmo. De acordo com Webb e Hassel (apud Op. cit., p. 13-14) existem cinco famílias de modelos em geral:

- modelos de sistemas dinâmicos;

- modelos de distribuição espacial;

- modelos qualitativos do raciocínio lógico;

- modelos de eventos probabilísticos;

- modelos de análise de dados.

$\mathrm{Na}$ Física, muitos modelos representam sistemas dinâmicos, isto é, os modelos que estabelecem alguma espécie de relação matemática entre quantidades físicas e o tempo, considerado como uma variável independente. São estes os modelos que serviram como nosso objeto de estudo. Buscando evidenciar as potencialidades do Modellus, Teodoro o analisa através de dois pontos de vista.

Do ponto de vista computacional, o programa pode ser visto como um micromundo no computador para uso tanto dos estudantes quanto dos professores, não sendo baseado numa metáfora de programação. Na "janela do modelo" o usuário pode escrever modelos matemáticos, quase sempre da mesma forma que a manuscrita do dia-a-dia, dispensando o aprendizado de uma nova linguagem para a elaboração desses modelos.

Do ponto de vista educacional, o Modellus incorpora tanto os modos expressivos quanto os modos exploratórios das atividades de aprendizagem (BLISS; OGBORN apud TEODORO, 1998). Em uma atividade de aprendizado expressiva, os estudantes podem construir seus próprios modelos matemáticos e criar diversas formas para representá-los. Em um modo exploratório, os alunos podem usar modelos e representações feitas por outros, analisando como grandezas diferentes se relacionam entre si ou visualizando a simulação de um evento físico. O delineamento pedagógico do Modellus admite que o computador é uma ferramenta cognitiva, mas não substitui habilidades humanas de alta ordem, ou seja, assume-se que o Modellus auxilia na aprendizagem, mas que a "inteligência, emoção, cultura, poesia e arte residem no usuário, não no software" (TEODORO, 1998).

Os autores deste trabalho, embasados nas ideias já apresentadas anteriormente, elaboraram um roteiro de atividades fazendo uso do software Modellus e envolvendo situações de cinemática, em especial o MRU. O objetivo principal deste conjunto de atividades é construir o conceito de velocidade média a partir dos conceitos de distância e tempo.

Cabe ressaltar que todas as atividades foram criadas pelo grupo de pesquisadores. Estas foram desenvolvidas com características que corroboram com as ideias descritas no referencial deste trabalho no que se refere ao ensino de Ciências e as potencialidades de se trabalhar com a modelagem computacional. 
Ainda sobre o aprender cientificamente, Moreira (2014, p. 17) aponta que:

\begin{abstract}
Aprender significativamente envolve pensar, é claro, mas esse pensar envolve imaginar, fazer analogias, buscar diferenças e semelhanças, fazer aproximações, modificar, matematizar, informatizar, analisar criticamente, teorizar, argumentar, etc., não necessariamente nesta ordem. Tudo isso para quê? Para ir modelando os novos conhecimentos recebidos, ou para ir construindo novos conhecimentos através da modelagem.
\end{abstract}

Deve-se caminhar nesta direção, pois "Simplesmente estimular, exigir a memorização de respostas, fórmulas, equações, algoritmos é um ensino não só ineficaz, mas também anticientífico" (MERVIS, 2013, p. 212, tradução nossa).

Inicialmente os participantes do curso exploraram o software seguindo um roteiro para construir uma simulação computacional sobre MRU. A proposta das atividades objetivou a exploração e a construção de modelos como um processo de interação (experimentoprofessor-aluno). A exploração do modelo faz com que o professor/aluno se questione constantemente sobre os efeitos de suas ações sobre os resultados gerados pelo modelo, normalmente esta questão pode ser descrita como: - se eu alterar "isso" o que acontece com "aquilo"? Este raciocínio causal subjacente servirá como pano de fundo para a promoção da interatividade. As atividades de ensino elaboradas visam levar o professor/aluno a questionar-se sobre as relações existentes, entre os conceitos cinemáticos e os gráficos do movimento de um determinado móvel em questão. Vale frisar que os participantes construíram o modelo, e depois exploraram o conjunto de atividades proposto (Quadro 1). A estratégia é levar aos alunos o modelo já construído e fazer uso das atividades, que foi o caso dos professores deste curso de formação. Caso os alunos já estejam familiarizados com o Modellus, pode-se também construir o modelo em sala de aula.

A interface final da simulação inicial proposta, descrita no parágrafo anterior, é apresentada na Fig. 01.

A Fig. 01 mostra uma simulação na qual se tem os objetos: fusca, cachorro, gato e dinossauro que, para o tempo igual a zero, se encontram na origem de um eixo de sistema de coordenadas (menos o gato), e na situação final ocupam diferentes posições no eixo horizontal. Nesta imagem pode-se perceber que é possível explorar diversos conceitos que estão envolvidos no MRU, como: posição e velocidade negativa, referência vetorial, variações de posição entre outros. Na simulação foram explorados quatro movimentos distintos de MRU, de forma que ao desenvolver a simulação, a posição de cada objeto é representada na forma de estroboscopia em intervalos iguais de tempo. Pode-se observar na Fig. 02, a qual apresenta o gráfico de cada objeto, em que no eixo horizontal está representado o tempo, e no eixo vertical a posição. Aproximações com a Matemática foram realizadas a partir da interpretação dos parâmetros das equações das retas dos gráficos. Por serem retas descritas por equações do primeiro grau, o coeficiente linear representa a posição inicial e o coeficiente angular a velocidade média. 


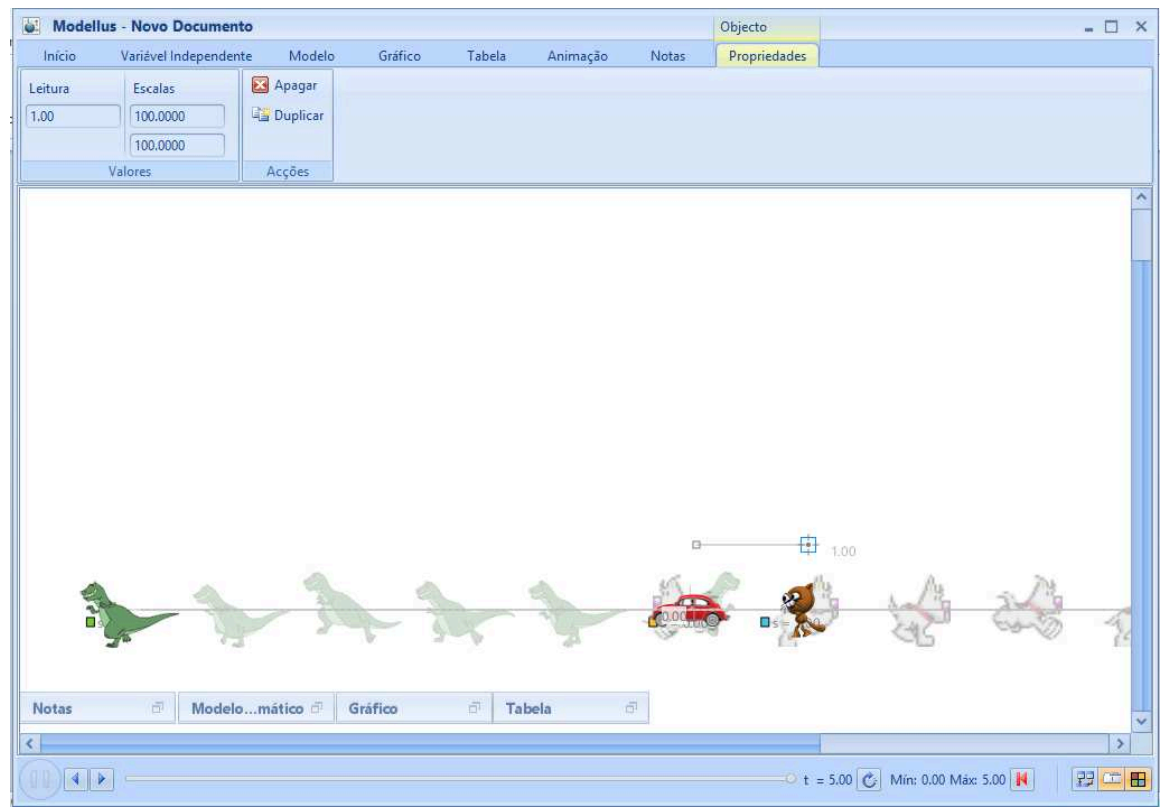

Fig. 1 -Modelagem do MRU. Fonte: Dos autores.

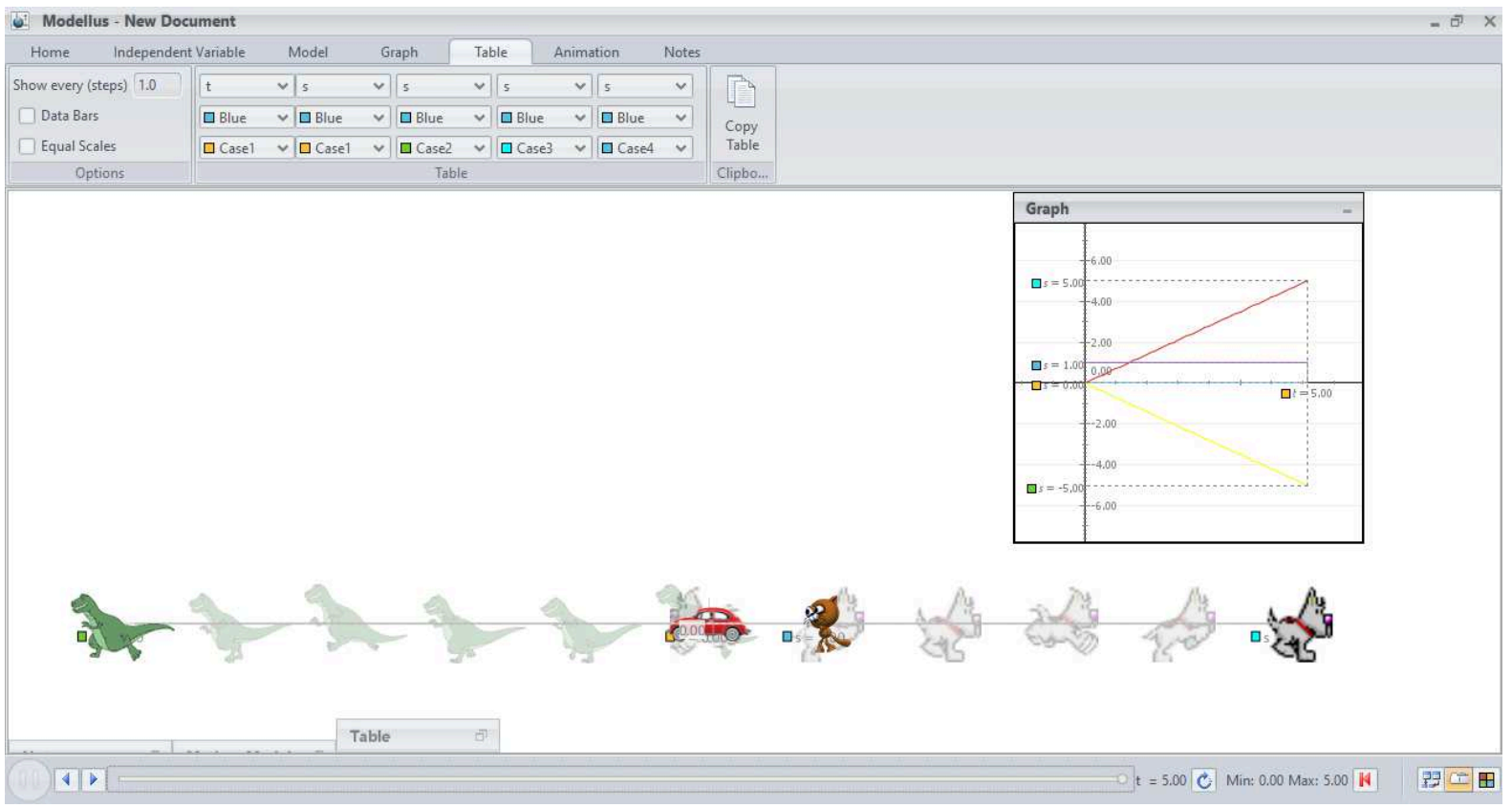

Fig. 02 - Modelagem do MRU - gráficos. Fonte: Dos autores.

A construção do modelo apresentado anteriormente foi fundamentada pelos pressupostos de Araújo, Veit e Moreira (2012), que em termos do Ensino de Ciências, e mais especificamente do ensino de Física, a questão que se coloca é: como atividades de ensino voltadas para os processos de elaboração e análise de modelos científicos podem contribuir para propiciar aos alunos uma aprendizagem dos conteúdos? 
Ainda segundo os autores (Ibidem, 2012), nas aulas convencionais de Física em cursos de nível Médio, não é rara a ocorrência de oscilações entre extremos no que diz respeito a atividades de ensino: em uma ponta, professores que associam o aprendizado a receitas de resolução de problemas, tendo algebrismos como foco; e em outra, docentes que abolem praticamente todo o formalismo necessário para uma compreensão adequada do conteúdo. Um desafio que se apresenta é de que maneira trazer elementos fundamentais em Ciência como a representação de fenômenos reais através de modelos, conceitos, trabalho colaborativo, formulação e teste de hipóteses, por exemplo, para a sala de aula. Portanto, foi sob a luz destes questionamentos que foi desenvolvido o modelo proposto. Não se deseja apresentar uma solução na forma de receita para responder essas questões, longe desta presunção apresenta-se apenas uma possibilidade viável de trabalhar em sintonia com os problemas elencados.

No Quadro 01 são apresentadas as atividades desenvolvidas referentes a esta simulação.

Quadro 01: Modelagem do MRU.

\section{Atividades}

1) Para iniciar as atividades abrir o arquivo "ModelagemMRU.mrl". Após aberto o arquivo, clique uma vez nos ícones conforme a Fig. 03.

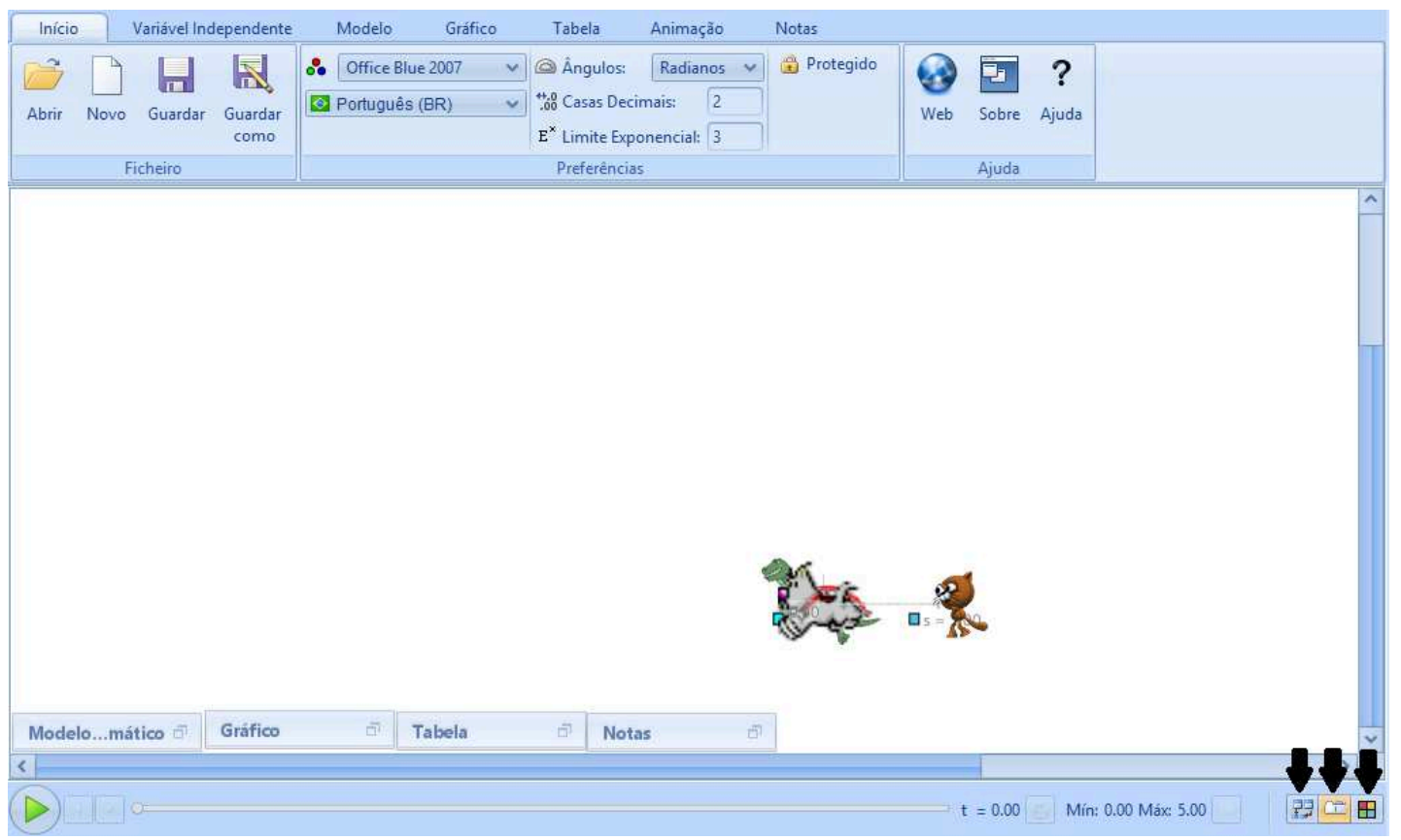

Fig. 03: Iniciando as atividades. Fonte: Dos autores.

2) Clicar no botão play e observar o movimento de cada objeto.

3) Como é o movimento de cada objeto?

4) Há algum objeto que permanece em repouso?

5) Quanto ao movimento do cachorro e do dino, o que pode-se perceber? 
6) Considerando a posição final da simulação $(t=5 \mathrm{~s})$, utilize a régua virtual do Modellus para medir as distâncias entre os objetos conforme o Quadro 01.

Quadro 01: Distância entre os objetos.

\begin{tabular}{|l|c|c|c|c|}
\hline & Fusca & Dino & Gato & Cachorro \\
\hline Fusca & 0 & & & \\
\hline Dino & & 0 & & \\
\hline Gato & & & 0 & 0 \\
\hline Cachorro & & & & \\
\hline
\end{tabular}

7) Utilize o plano cartesiano para representar a posição final de cada objeto no eixo horizontal, de forma que a posição do fusca esteja localizada na origem $(0,0)$.

8) Preencha o Quadro 02 para cada objeto observando sua posição para cada instante no tempo. Observe as marcas da água para auxiliar na obtenção dos valores.

Quadro 2: Posição x Tempo.

\begin{tabular}{|c|l|l|l|l|}
\hline $\begin{array}{c}\text { Objeto } \\
\text { Tempo }\end{array}$ & Fusca & Dino & Gato & Cachorro \\
\hline 0 & & & & \\
\hline 1 & & & & \\
\hline 2 & & & & \\
\hline 3 & & & & \\
\hline 4 & & & & \\
\hline 5 & & & & \\
\hline
\end{tabular}

9) No Modellus, clique no botão indicado na Fig. 04, e em seguida maximize a janela tabela. Compare o seu quadro com a tabela do software. Há diferenças? Se sim, quais? 


\section{的.}

Fig. 04: Habilitando abas.

10) Utilize o plano cartesiano para construir um gráfico que represente a posição em função do tempo $\mathrm{p}$ x t para cada um dos objetos.

11) No Modellus, maximize a janela gráfico. Compare o seu gráfico com o do software.

12) Considerando o quadro da questão 8 , observe a primeira e a quinta coluna. A cada segundo que passa quantos metros o cachorro se desloca? Você saberia informar a posição do cachorro após 20s? E após 100s?

13) Considere agora que o cachorro se desloca o dobro da distância no mesmo intervalo de tempo. Após 20s, qual seria sua posição?

14) Considerando a situação inicial, qual o deslocamento do cachorro em 1s? Esse valor é o deslocamento que um objeto faz no intervalo de tempo de $1 \mathrm{~s}$, e é conhecido como velocidade média.

15) Compare as velocidades médias do cachorro e do dino. São iguais? Explique.

16) Trazer um software para aprimorar o conceito do sentido da velocidade.

Fonte: Dos autores.

As atividades foram desenvolvidas com características investigativas, por meio de um roteiro mais aberto, o qual permite intervenções ou modificações por parte do aluno durante sua aplicação. Fazendo com que a aula seja construída conforme o desenvolvimento dos estudantes ao longo de discussões, verificações e revalidações de hipóteses e respostas. Desta forma o aluno tem a oportunidade de ir construindo e modelando seu conhecimento, sendo o protagonista no processo de aprendizagem.

\section{Resultados}

A análise dos resultados refere-se à criação das atividades propostas pelo grupo de professores pesquisadores, à percepção dos professores participantes do curso ao desenvolverem as atividades, doze professores no total, e à percepção dos alunos da Educação Básica ao manipularem o software, que foi desenvolvido na sala de aula de dois professores participantes do curso de formação. 
Quanto à criação das atividades pode-se inferir que o grupo de pesquisadores considera fundamental que o professor tenha domínio mínimo sobre a ferramenta que vai trabalhar, para que por meio dela possa criar e desenvolver atividades desafiadoras e instigantes para o aluno. Além disso, ao trabalhar com tecnologias podem surgir "problemas" do tipo o aluno ter clicado em um lugar indesejado, ou ter inserido valores errados, ou o software parar de funcionar, por isso é importante que o professor neste momento olhe para a tela virtual e consiga resolver a situação. Também surgem muitas perguntas e dúvidas por parte dos alunos quando se trabalha com algo novo. Mas, ao mesmo tempo, todos acabam aprendendo juntos, muitas vezes problemas operacionais da máquina os alunos acabam resolvendo sozinhos.

Em relação aos relatos dos professores participantes do curso quanto a suas expectativas e experiências quando desenvolveram as atividades no curso, suas percepções são que a utilização do software foi positiva, tanto pelo desenvolvimento da programação como pela exploração das atividades.

[...] eu faria a modelagem também, sabe por que, porque às vezes a gente peca em não proporcionar essas oportunidades, e às vezes numa turma de vinte, trinta alunos, nós teríamos 1, que despertaria para esse lado de programação, para esse lado mais de pensar na coisa, e a gente deixa de oferecer isso pra eles, porque daqui a pouco eles gostam de informática, não todos, não tenho a esperança do que mais do que um ou dois, mas numa turma lá alguém vai despertar e vai mexer por conta. (PROFESSORA 3).

Neste momento é possível perceber a preocupação da professara com a possibilidade de desenvolver o gosto pela programação já em nível de Ensino Médio, o que vem de encontro com o trabalho de Resnick (2013) em que desenvolve uma reflexão crítica sobre a fluência dos nativos digitais em relação ao uso de tecnologias, discutindo que consumir não implica em entender o potencial de criação dos recursos tecnológicos.

Quanto ao desenvolvimento de outras atividades os professores acreditam ser possível criar outras simulações com roteiros para serem realizados pelos alunos. "[...] para gente fazer uma outra, eu acho que é importante, eu tentaria fazer com os meus alunos" (PROFESSORA 3). Uma questão seria o tempo dedicado para desenvolver a simulação, porém também é possível encontrar simulações prontas na internet e caberia ao professor desenvolver apenas as atividades a partir da simulação.

No que se refere à utilização desta ferramenta os professores relatam que trabalhar com tecnologias deve ser algo motivacional para o aprendizado do aluno, pois possibilita uma visão diferente daquela que ele está habituado, mostrando que a Física não se resume a fórmulas e temas fragmentados. $\mathrm{O}$ aspecto da visualização também é algo positivo apontado pelos professores, facilitando a compreensão, pois apresenta a construção ao mesmo tempo do gráfico, da tabela e da simulação. 
Eu acho que tem várias diferenças, uma é motivacional, o aluno, no fato de sentar em outro lugar, de ter o computador, é motivação pro lado da física, e acho que quebra um pouquinho aquela barreira de que física é só difícil, é só calcular. E aqui ele faz todo um outro pensamento que não é só o cálculo, a formalidade matemática, e eu acho que visualizar ali os objetos, e enxergar o gráfico junto, eu acho que é muito difícil de conseguir passar isso pro aluno em sala de aula, a gente se vira, mas tu mostra tudo fragmentado, uma parte, depois a outra, depois a outra, não que também não é importante, mas juntar tudo. (PROFESSORA 3).

[...] para ele visualizar todo um movimento, e as várias formas de representar, a tabela, o gráfico, a posição ali assim, a posição, tudo isso junto, por que às vezes, trabalha uma parte né, depois a outra, e aí eles não, aí eles confundem tudo né, o que é o gráfico, o que é a representação das posições. (PROFESSORA 4).

$\mathrm{Na}$ fala destas duas professoras está implícito o potencial da visualização, distinguese o processo de poder visualizar o gráfico junto com a animação. Isso pode ser interpretado por representações múltiplas, e de acordo com Borba e Villarreal (2004), representações múltiplas promove a aprendizagem de conceitos abstratos, de difícil compreensão, de forma que a visualização é fator importante ao se utilizar representações múltiplas, e as tecnologias se apresentam atualmente como ferramentas potentes para se explorar a visualização.

No que se refere às atividades aplicadas com os alunos destacam-se falas de duas professoras que expõem a realidade de algumas escolas, em relação a aspectos materiais que influenciam na sua prática com uso de tecnologias. Uma das professoras relatou que, a "escola não disponibiliza o laboratório de informática com muita facilidade" (PROFESSORA 12). Em corroboração, outra participante ressalta:

O ideal seria ter um bom equipamento, um ambiente propício para o uso, internet com navegação excelente para não ser lento se utilizado online, falta de monitores que consigam reparar imediatamente os erros que possivelmente venham ocorrer e ter uma turma pequena que o professor consiga sanar todas as dúvidas (PROFESSORA 11).

As autoras das falas, ainda se referem aos laboratórios de informática como local específico para as práticas, talvez pelo fato de muitas escolas privadas e públicas serem equipadas com essas salas e que de alguma maneira o professor termina utilizando-a de forma esporádica, esquecendo-se da presença massiva das tecnologias móveis digitais na escola, ou seja, os celulares em contextos de escolas urbanas.

Já quando relatam sobre suas experiências com uso do Modellus, uma professora destaca sua dificuldade quanto ao uso do laboratório de informática: 
[...] tive dificuldade na questão do laboratório lá, eu pedi pro técnico baixar o Modellus e quando cheguei lá tinha vinte e quatro computadores e tinha uns dez, doze que não estavam funcionando. O computador não estava ligando, os alunos entraram lá, colocaram senha e não conseguia acessar. Então, era uma turma de quase trinta alunos com poucos computadores, eles ficaram em vários em um computador. Mas mesmo assim, valeu a pena. (PROFESSORA 1).

Mesmo com dificuldades de espaço e poucos computadores a professora acreditou no potencial do software para trabalhar com seus alunos. Sentiu-se confiante, talvez pelo fato de ter vivenciado primeiramente as atividades no curso, para depois desenvolvê-las com seus alunos. A socialização, as sugestões de integração e as atividades desenvolvidas por alguns participantes com os alunos em sala de aula encorajaram os demais a trabalhar nas suas salas de aula atividades com recursos tecnológicos, a desenvolverem os conhecimentos construídos no decorrer dos encontros, em situações que envolvessem a utilização de recursos tecnológicos. A socialização acabou tendo um caráter incentivador pelo fato dos professores que relataram inicialmente sua experiência terem tido uma percepção positiva em decorrência da motivação que observaram nos estudantes e a maior facilidade de resolver os problemas quando comparada com a forma tradicional que trabalhavam, assim sendo, contribuíram com os demais professores, pois "a troca de experiências e o compartilhamento de saberes consolidam espaços de formação mútua, nos quais cada professor é chamado a desempenhar, simultaneamente, o papel de formador e de formando" (NÓVOA, 2015, texto digital).

Destaca-se ainda que estas atividades envolvendo o Modellus foram conduzidas por duas professoras em suas salas de aula, uma de Física que explorou o MRU e outra de Matemática que trabalhou com funções, ao mesmo tempo com a turma, fazendo aproximações da Física com a Matemática. Os outros professores do curso de formação escolheram outros aplicativos para desenvolvimento em suas aulas. $\mathrm{O}$ seguinte relato descreve a percepção de um dos professores sobre a atividade desenvolvida em sua sala de aula.

[...] começou a parte teórica do movimento uniforme, ai eu consegui mostrar pra eles, de novo eи peguei umas funções horárias e coloquei no Modellus e mostrava pra eles e colocava dois movimentos em que ocorria encontro e ai quando eles vão trabalhar a parte de cálculo eles começam a localizar, compreender, eles entendem a situação do movimento lá, relaciona com o gráfico, com a tabela. Eu acho que isso tá dando um resultado bem melhor que nos outros anos. (PROFESSORA 1).

O relato da professora evidencia que quando os alunos foram trabalhar com a equação, ou seja, desenvolver cálculos, recorreram e relacionaram com o gráfico, a tabela e a animação. Desta forma pode-se perceber que para os alunos, as equações estão conectadas com alguma situação, mesmo não sendo a realidade, a animação é um modelo que vem representar a realidade de forma simplificada. Para além, ao relacionar com o gráfico e a tabela, o aluno 
desenvolve um processo mais sofisticado de análise e compreensão da situação. Este movimento pode possibilitar o entendimento e a apropriação de modelos científicos de forma autônoma, como Araújo, Veit e Moreira (2012) preconizam em seu trabalho, sem priorizar algebrismo e abandonar o formalismo. Da mesma forma, este movimento vai ao encontro do que se procura no ensino científico, pois Pietrocola (1999) alerta da necessidade de se fazer o ensino de ciências com clareza do que é ciência, que se deve procurar possibilitar aos alunos uma vivência do processo científico ao realizar o ensino de ciências para que os alunos não tenham concepções falsas de ciências, ou seja, que a ciência é algo estático, contido num livro, não falseável e produto de momentos únicos de um cientista gênio. Ao compreender que a ciência é um conjunto de esforços de múltiplos indivíduos que podem errar, que representa uma forma simplificada de compreender os fenômenos naturais, o aluno pode se encorajar a resolver problemas científicos apresentados em suas aulas, ultrapassando assim a barreira que existe em relação a dificuldade e falta de motivação nas aulas de ciências e matemática.

Em seus depoimentos, pode-se perceber nos gestos e expressões dos professores a satisfação pelo uso da tecnologia e pelo desempenho alcançado por eles diante das atividades propostas. Em um dos relatos destaca-se a importância da visualização para o entendimento dos tipos de movimento e o conceito de velocidade negativa.

A visualização da animação fez ele entender e relacionar. O movimento é progressivo, o movimento é retrógado. Então eles entenderam essa questão também. O que é o sinal da velocidade (PROFESSORA 1).

Araujo, Veit e Moreira (2008, p. 1139, tradução nossa) quando se referem à modelagem computacional afirmam que:

[...] atividades de modelagem exercem uma influência positiva na predisposição do indivíduo em aprender Física. Isto ocorre quando os estudantes percebem a relevância de algumas relações matemáticas e conceitos durante a interação com modelos conceituais. Elementos que anteriormente pareciam ser muito abstratos se tornam familiar e mais concretos.

Outro aspecto a destacar é o olhar dos alunos diante desta experiência que pelo relato da professora foi uma experiência muito positiva, pois eles entenderam rapidamente onde tinham que clicar, o inconveniente foi o laboratório estar com poucos computadores disponíveis, fato que não possibilitou que todos interagissem com o software.

[...] chegaram lá já mexendo. Eu até disse: vejam o gráfico agora e eles já tinham mexido. Mas eles trabalharam, claro que uma parte deles fazerem sozinhos ali ficou um pouco mais difícil em função do laboratório que tava com poucos computadores. (PROFESSORA 1). 
Os professores relataram que perceberam uma maior facilidade por parte dos estudantes ao resolverem problemas posteriores. Afirmaram que estes os realizaram de forma mais rápida e em muitos momentos sem o uso de fórmulas, resolveram apenas fazendo comparações e relações com a animação explorada no Modellus, o que Moreira (2014) define como "aprender significativamente".

[...] estávamos fazendo exercícios, em sala de aula e um não estava conseguindo fazer, determinar a posição do móvel em determinado instante pela função e ele foi pela lógica. Ele disse: bom o que eu quero. Ele entendeu a situação. Não foi o cálculo por substituir o tempo e calcular a posição. Ele foi fazendo, a velocidade é tanto a partir de tal ponto, a posição final dele é essa (PROFESSORA 1).

[...] percebi o resultado na hora de fazer os exercícios no caderno que eles entenderam, alguns que sentiam dificuldade fizeram muito mais rápido que nos outros anos (PROFESSORA 1).

Cabe salientar que em todos os momentos o grupo de professores participantes da formação estava amparado e com o apoio do grupo de pesquisadores e de bolsistas que compõe a equipe do curso. Este fato, segundo relatos de alguns professores, foi um fator determinante para encorajá-los a experimentar essa nova metodologia em suas práticas pedagógicas.

\section{Considerações}

Neste trabalho foram utilizados como instrumento de coleta de dados as transcrições das falas dos professores, gravadas durante o curso de formação continuada. Foram apresentadas no capítulo anterior as consideradas mais relevantes para este trabalho, na forma de excertos, em que foi desenvolvida uma análise descritiva. Também foram utilizadas as anotações de campo dos pesquisadores, exploradas de forma mais detalhada durante a análise dos resultados, novamente referente a este recorte do curso de formação, em específico a parte de modelagem com o software Modellus e a socialização dos professores.

Em síntese pode-se dividir os resultados em três fatos distintos. No que se refere ao curso de formação continuada, foram abordados tópicos como compartilhamento de experiências, segurança para desenvolver a nova prática, o desenvolvimento de trabalhos conjuntos e a preocupação dos professores em relação a aprendizagem de programação no Ensino Médio. A socialização de experiências de professores que foram marcadas por vivências significativas pode vir a deixar seus pares mais seguros para que enfrentem novos desafios. No caso deste trabalho, os professores argumentaram que os seus alunos se mostraram mais motivados e resolveram de forma diferente as situações quando comparada com a forma tradicional. Dois professores desenvolveram em sua sala de aula a atividade de modelagem. Em relação a estas intervenções têm-se como principais características relatadas: motivação, visualização, repre- 
sentações múltiplas e aproximações da física com a matemática. Pode-se inferir que os alunos utilizaram diferentes estratégias, sem priorizar o algebrismo ou abandonar o formalismo, possivelmente vindo a compreender modelos científicos de forma autônoma. Por último, vale ressaltar as dificuldades técnicas enfrentadas pelos professores como: falta de computadores, dificuldade para reservar o laboratório de informática, computadores antigos e internet lenta.

Nesta perspectiva, o grupo de pesquisa considera que a formação continuada pode ser um dos caminhos possíveis para que os professores comecem a utilizar recursos tecnológicos, em especial a modelagem computacional, na abordagem de conteúdos de Ciências. Vale ressaltar que essa abordagem não deve, de forma alguma, substituir as atividades experimentais no Ensino de Ciências, deve ser utilizada no sentido de complementar ou elucidar questões que sejam impossíveis ou difíceis a partir da experimentação.

Outro aspecto é o de que o processo de modelagem contribui para uma melhor compreensão do que é fazer Ciência. O estudante percebe a Física de maneira mais ampla e com aplicabilidade dos conteúdos de conhecimento que ele constrói relativos aos mais diversos campos da Ciência.

Os aspectos abordados neste trabalho não exploraram todo o assunto, porém, podem concretizar a aprendizagem em uma perspectiva mais significativa para o estudante e favorecer o acompanhamento desse processo por parte do professor. Portanto, pode-se inferir que a experiência vivenciada foi significativa, por contribuir na aprendizagem dos estudantes e motivar o professor integrar os aplicativos computacionais em sua prática pedagógica.

\section{Referências}

ARAÚJO, I. S.; VEIT, E. A.; MOREIRA, A. M. Physics students’ performance using computational modelling activities to improve kinematics graphs interpretation. Computers and Education, v. 50, n. 4, p. 1128-1140, 2008.

ARAÚJO, I. S.; VEIT, E. A.; MOREIRA, A. M. Modelos computacionais no ensinoaprendizagem de física: um referencial de trabalho. Porto Alegre: Investigações em Ensino de Ciências, v. 17, n. 2, p. 341-366, 2012.

BONA, B. O. Análise de softwares educativos para o ensino de matemática nos anos iniciais do ensino fundamental. Experiências em Ensino de Ciências, v. 4, n. 1, p. 35-55, 2009.

BORBA, M. C.; Villarreal, E. M. Humans-with-Media and the Reorganization of Mathematical Thinking. United States of America: Springer, 2004.

BRANDÃO, R. V.; ARAUJO, I. S.; VEIT, E. A. A modelagem científica de fenômenos físicos e o ensino de Física. Física na Escola, São Paulo, v. 9, n. 1, 2008.

COLL, C; MAURI, T.; ONRUBIA, J. A incorporação das tecnologias da informação e da comunicação na educação: do projeto técnico-pedagógico ás práticas de uso. In: COLL, C.; 
MONEREIO, C. (Orgs.). Psicologia da Educação Virtual: aprender e ensinar com as tecnologias da informação e da comunicação. Tradução: Naila Freitas. Porto Alegre: Artmed, 2010 .

DAMASCENO, H. L. Os tablets chegaram: as tecnologias móveis nas escolas de Salvador/Bahia. 2014. 102 f. Dissertação (Mestrado) - Faculdade de Educação, Universidade Federal da Bahia, Salvador.

FAZENDA, C. A.; TAVARES, D. E.; GODOY, H. P. Interdisciplinaridade na pesquisa científica. Brasil: Papirus, 2015.

MEDEIROS, A.; MEDEIROS, C. F. Possibilidades e limitações das simulações computacionais no Ensino de Física. Revista Brasileira de Ensino de Física, v. 24, n. 2, 2002.

MERVIS, J. Transformation is possible if a university really cares. Science, v. 340, p. 292296, 2013.

MOREIRA, M. A. Modelos científicos, modelos mentais, modelagem computacional e modelagem matemática: aspectos epistemológicos e implicações para o ensino. Revista Brasileira de Ensino de Ciência e Tecnologia, v. 7, n. 2, p. 1-20, 2014.

NEIDE, I. G.; QUARTIERI, M. T. Recursos tecnológicos nos processos de ensino e de aprendizagem da Matemática e da Física. In: DULLIUS, M. M.; QUARTIERI, M. T. (Orgs.). Aproximando a Matemática e a Física por meio de Recursos Tecnológicos: Ensino Médio. Lajeado: Univates, 2016. cap.1, p.9-14.

NÓVOA, A. Formação de professores e profissão docente. 1992. Repositório da Universidade de Lisboa. Disponível em: <http://hdl.handle.net/10451/4758>. Acesso em: 13 out. 2015 .

PIETROCOLA, M. Construção e Realidade: O Realismo Científico de Mário Bunge e o Ensino de Ciências através de Modelos. Investigações em Ensino de Ciências, v. 4, n. 3, p. 213-227, 1999.

RESNICK, M. Mother's Day, Warrior Cats, and Digital Fluency: Stories from the Scratch Online Community. In: THE CONSTRUCTIONISM 2012 CONFERENCE: THEORY, PRACTICE AND IMPACT, 2012, Greece. Proceedings...

SANTOS, A. B. A Física no Ensino Médio: motivação e cidadania (Relatos de Experiência). Em Extensão, v. 8, n. 1, p. 60-71, 2009. Disponível em: <http://www.seer.ufu.br/index.php/ revextensao/article/view/20381/10851>.

SCHUHMACHER, V. R. N.; ALVES FILHO, J. P.; SCHUHMACHER, E. As barreiras da prática docente no uso das tecnologias de informação e comunicação. Ciência e Educação, v. 23, n. 3, p. 563-576, 2017. 
PRENSKY, M. Digital Natives, Digital Immigrants Part 1. On the Horizon, v. 9, n. 5, p. 1-6, 2001.

TEODORO, V. D. From formulae to conceptual experiments: interactive modelling in the physical sciences and in mathematics. In: INTERNATIONAL COLOS CONFERENCE NEW NETWORK-BASED MEDIA IN EDUCATION, 1998, Maribor, Slovenia. p. 13-22. 